\title{
Targeting of the BRAF gene in papillary thyroid carcinoma (Review)
}

\author{
YAQIONG LI $^{1,3}$, MISA NAKAMURA ${ }^{2}$ and KENNICHI KAKUDO ${ }^{1}$ \\ ${ }^{1}$ Department of Human Pathology, Wakayama Medical University, Wakayama; ${ }^{2}$ Department of Rehabilitation, \\ Osaka Kawasaki Rehabilitation University, Osaka, Japan; ${ }^{3}$ Department of Pathology and \\ Pathophysiology, Shandong University School of Medicine, Jinan, P.R. China
}

Received February 13, 2009; Accepted April 13, 2009

DOI: $10.3892 /$ or_00000487

\begin{abstract}
Papillary thyroid carcinoma (PTC) is the most common type of thyroid malignancy and includes several histological variants. Patients suffering from PTC usually have a good outcome. However, a group of PTC patients still encounter high rates of recurrence and mortality. The $\mathrm{BRAF}^{\mathrm{V} 600 \mathrm{E}}$ mutation is the most common genetic alteration identified in PTC, ranging from 29 to $83 \%$, with the average rate about $40 \%$. To date, a growing body of evidence has suggested that the BRAFV600E mutation plays an important role in the carcinogenesis of PTC, and it tends to be associated with special subtypes of PTC and predicts poor prognosis. Therefore, mutant BRAF has become an attractive cancer target for PTC. This article is focuses on reviewing the impact of the BRAF ${ }^{\mathrm{V} 600 \mathrm{E}}$ mutation in the tumorigenesis of PTC, differences in the prevalence of the $\mathrm{BRAF}^{\mathrm{V} 600 \mathrm{E}}$ mutation in variants of PTC, and its detection methods. The novel advantages of the $\mathrm{BRAF}^{\mathrm{V} 600 \mathrm{E}}$ mutation-targeted therapies in studies of PTC are also discussed.
\end{abstract}

\section{Contents}

1. Introduction

2. The $\mathrm{BRAF}^{\mathrm{V} 600 \mathrm{E}}$ mutation in the carcinogenesis of papillary thyroid carcinoma

3. The BRAF ${ }^{\mathrm{V} 600 \mathrm{E}}$ mutation in common type and histological variants of papillary thyroid carcinoma

4. Prognostic value of the BRAFV600E mutation

5. Detection of the BRAF ${ }^{\mathrm{V} 600 \mathrm{E}}$ mutation

6. Novel advantages in $\mathrm{BRAF}^{\mathrm{V} 600 \mathrm{E}}$ mutation-targeted therapy

7. Conclusion and perspective

Correspondence to: Dr Kennichi Kakudo, Department of Human Pathology, Wakayama Medical University, Kimiidera 811-1, Wakayama 641-8509, Japan

E-mail: kakudo-k@wakayama-med.ac.jp

Key words: thyroid, papillary carcinoma, $\mathrm{BRAF}^{\mathrm{V} 600 \mathrm{E}}$ mutation, histological variants, signaling pathway, prognosis, target therapy

\section{Introduction}

Thyroid cancer represents the most common malignant tumor of the human endocrine system and its incidence has increased significantly during the past decades in many area of the world $(1,2)$. The traditional classification of thyroid carcinoma divided these malignancies into four groups, including papillary, follicular, medullary and anaplastic carcinomas (3). Among the above four types of thyroid carcinoma, papillary thyroid carcinoma (PTC) is the most prevalent type, accounting for approximately $80 \%$ of all thyroid malignancies in western countries (4) and more than $90 \%$ in Japan (5). PTC shows an excellent overall survival rate of greater than $90 \%$ and particularly for patients younger than 45 years old (3). Although it is relatively indolent and highly curable, up to $10 \%$ of patients with PTC eventually die as a result of this disease (6).

PTC is associated with characteristic genetic alterations, which have been shown to play an important role in thyroid carcinogenesis. These include rearrangement of the tyrosine kinase receptor oncogenes RET or NTRK1 $(7,8)$ and point mutations of the RAS and BRAF genes (9-11). Among these, $\mathrm{BRAF}^{\mathrm{V} 600 \mathrm{E}}$ mutation is the most common genetic change in PTC and is present in about $29-83 \%$ of cases (12). Recently, a growing body of reports in the literature indicates that the distribution of the BRAF ${ }^{\mathrm{V} 600 \mathrm{E}}$ mutation shows a clear genotype-phenotype correlation. It has been suggested that the $\mathrm{BRAF}^{\mathrm{V} 600 \mathrm{E}}$ mutation has a strong association with classic papillary structure and tall cell variant of PTC but not related to the follicular variant (13). This may be one of the most important reasons to explain the variety of prevalences of the $\mathrm{BRAF}^{\mathrm{V} 600 \mathrm{E}}$ mutation in different reports, because they analyzed different sub-histological compositions of PTC without additional subtype stratification. Although direct sequencing has been considered as the gold standard method for detecting the BRAF ${ }^{\mathrm{V} 600 \mathrm{E}}$ mutation, a variety of other methods have also been demonstrated to be highly sensitive and specific, which may be one factor contributing to wide discrepancies in reports on the BRAF ${ }^{\mathrm{V} 600 \mathrm{E}}$ mutation frequency (14-21).

Although a majority of studies showed a significant association of the BRAF ${ }^{\mathrm{V} 600 \mathrm{E}}$ mutation with one or more conventional high-risk clinicopathological characteristics and/or poor prognosis of patients with PTC (22), some contro- 
versial findings were also reported by other investigators (23-25).

This article will focus on reviewing the BRAFV600E mutation in the carcinogenesis of PTC, the association between the $\mathrm{BRAF}^{\mathrm{V} 600 \mathrm{E}}$ mutation and different histological subtypes of papillary thyroid carcinoma, the types of methods available to detect the $\mathrm{BRAF}^{\mathrm{V} 600 \mathrm{E}}$ mutation, its prognostic significance, and finally the novel advantages of $\mathrm{BRAF}^{\mathrm{V} 600 \mathrm{E}}$ mutationtargeted therapy of PTC is also discussed.

\section{The BRAF ${ }^{\mathrm{V} 600 \mathrm{E}}$ mutation in the carcinogenesis of papillary thyroid carcinoma}

The RAS-RAF-MEK-ERK signaling pathway (MAPK pathway) is a classical conserved intracellular signaling pathway that plays a fundamental role in cellular proliferation, differentiation, apoptosis, and survival. When activated aberrantly, it can induce tumorigenesis (12). This signaling pathway is particularly important for thyroid cancer because it harbors several genetic alterations in this pathway with a high prevalence, including rearrangement of the tyrosine kinase receptor oncogenes RET or NTRK $(7,8)$ and point mutations in the RAS or RAF genes (9-11). Indeed, these mutations are found in $\sim 70 \%$ of all PTC cases and rarely overlap in the same tumor $(11,26,27)$. Specific rearranged forms of RET were detected in PTC and are the result of double-stranded DNA breaks (mostly radiation-induced), which lead to erroneous reparative fusion of the $3^{\prime}$ portion of the RET gene to the 5 ' portion of a constitutively expressed unrelated gene, named RET/PTC (28). Approximately 17 different hybrid oncogenes have been reported and the most prevalent variants are RET/PTC1 and RET/PTC3, accounting for $>90 \%$ of all rearrangements (29). Similar rearrangements of neurotropic receptor tyrosine kinase type 1 (NTRK1) have also been described in a proportion of PTC patients (29). RAS point mutations are another genetic alteration in thyroid cancer. These involve specific sites (codons 12,13 and 61) of the N-RAS, H-RAS or K-RAS genes and were frequently detected in follicular thyroid carcinoma (FTC, 40-50\%) (30) but relatively infrequently in PTC $(\sim 10 \%)$.

BRAF is a member of the RAF family of serine-threonine kinases, which include ARAF, BRAF and CRAF (RAF-1). Among the three isoforms of these RAF family members, BRAF has substantially greater basal kinase activity toward MEK than ARAF or CRAF. This difference between these isoforms of RAF kinase may due to CRAF and ARAF containing four distinct RAS-GTP-dependent phosphorylation sites for maximal activation, whereas BRAF has only two of these sites (31). This may be the molecular shortcut of BRAF to become activated by a single amino acid substitution. Recently, mutations in the BRAF gene were identified in a large-scale screen for genes mutated in human cancers. The BRAF $^{\mathrm{V} 600 \mathrm{E}}$ mutation, a T1799A transversion mutation (formerly referred to as the BRAF T1796A) in exon 15 of the gene, which causes a V600E (formerly termed V599E) amino acid substitution in the protein, is the most frequently reported BRAF mutation (>90\%) (32). A few other activated BRAF mutations have been reported in a small proportion of thyroid carcinomas, such as AKAP9-BRAF (33), K601E (34), V599ins (35), V600E+K601del (36,37), V600D+FGLAT601- 605ins (37), and a recently characterized new type of BRAF mutation, T599I-VKSR(600-603)del found in a follicular variant of PTC (38).

Recently, the mechanism of BRAF activation has been elucidated (39). The BRAF ${ }^{\mathrm{V} 600 \mathrm{E}}$ mutation and most other mutations involve either the activation loop or the P loop (glycine-rich phosphate-binding loop) in the kinase domain. In the wild-type BRAF protein, the hydrophobic interaction between the activation loop and $\mathrm{P}$ loop maintains the protein in an inactive conformation. The presence of negatively charged glutamate in mutant BRAF destabilizes the regulatory interaction between the activation loop and $\mathrm{P}$ loop, resulting in hyperactivation of BRAF and hence the mitogen-activated protein kinase kinases MEK1 and MEK2. Activated MEK continues the cascade of phosphorylation events by activating extracellular signal-regulated kinase, ERK1 and ERK2. Once it is phosphorylated, ERK is translocated across the nuclear membrane, resulting in the activation of numerous transcription factors, which finally regulate the expression of a series of genes involved in proliferation, angiogenesis, metastasis, dedifferentiation, and anti-apoptosis of cancer (Fig. 1) (40-42). The carcinogenic ability of the $\mathrm{BRAF}^{\mathrm{V} 600 \mathrm{E}}$ mutation was elegantly demonstrated by in vitro and in vivo experiments. It can induce thyroid cell transformation in vitro and induce PTC in transgenic mice upon targeted expression of the BRAF V600E protein in the thyroid gland $(43,44)$.

$\mathrm{BRAF}^{\mathrm{V} 600 \mathrm{E}}$ mutations have been found at all stages of tumor progression, including micro-carcinoma, poorly differentiated thyroid carcinomas (PDC), and anaplastic thyroid carcinomas (ATC) that contain areas of well differentiated PTC and were believed to arise from PTC (45). In these poorly differentiated and anaplastic thyroid carcinomas, the $\mathrm{BRAF}^{\mathrm{V} 600 \mathrm{E}}$ mutation is detected in both poorly or anaplastic tumor areas and well differentiated papillary parts, demonstrating that the $\mathrm{BRAF}^{\mathrm{V} 600 \mathrm{E}}$ mutation occurs in the early stage of carcinogenesis and predisposes the cells to tumor dedifferentiation (41).

\section{The BRAF ${ }^{\mathrm{V} 600 \mathrm{E}}$ mutation in common type and histo- logical variants of PTC}

The BRAF ${ }^{\mathrm{V} 600 \mathrm{E}}$ mutation is the most common genetic event in sporadic PTC. A prominent finding on the BRAF $6000 \mathrm{E}$ mutation is its exclusive occurrence in PTC and PTC-derived ATC, and it does not occur in follicular thyroid carcinoma (FTC), medullary thyroid carcinoma (MTC), or benign thyroid tumors (adenoma or hyperplasia) (22). As reviewed by Xing et $a l$, the prevalence of the BRAF mutation ranges from 29 to $83 \%$ in PTC, with an average rate of approximate $40 \%$ (13). This strikingly wide variation in the prevalence of the $\mathrm{BRAF}^{\mathrm{V} 600 \mathrm{E}}$ mutation reported by different authors can be explained by the different histological subtype distribution of PTC.

Some PTC show special histological features, that is to say, a combination of certain growth patterns, cell types, and stromal reactions. Therefore, PTC can be further classified into several histologically distinct subtypes in accordance with the WHO classification of thyroid tumors, mainly including follicular, tall cell, columnar cell, oncocytic, diffuse sclerosing, solid, and clear cell variants (3). In 1995, Apel et al 


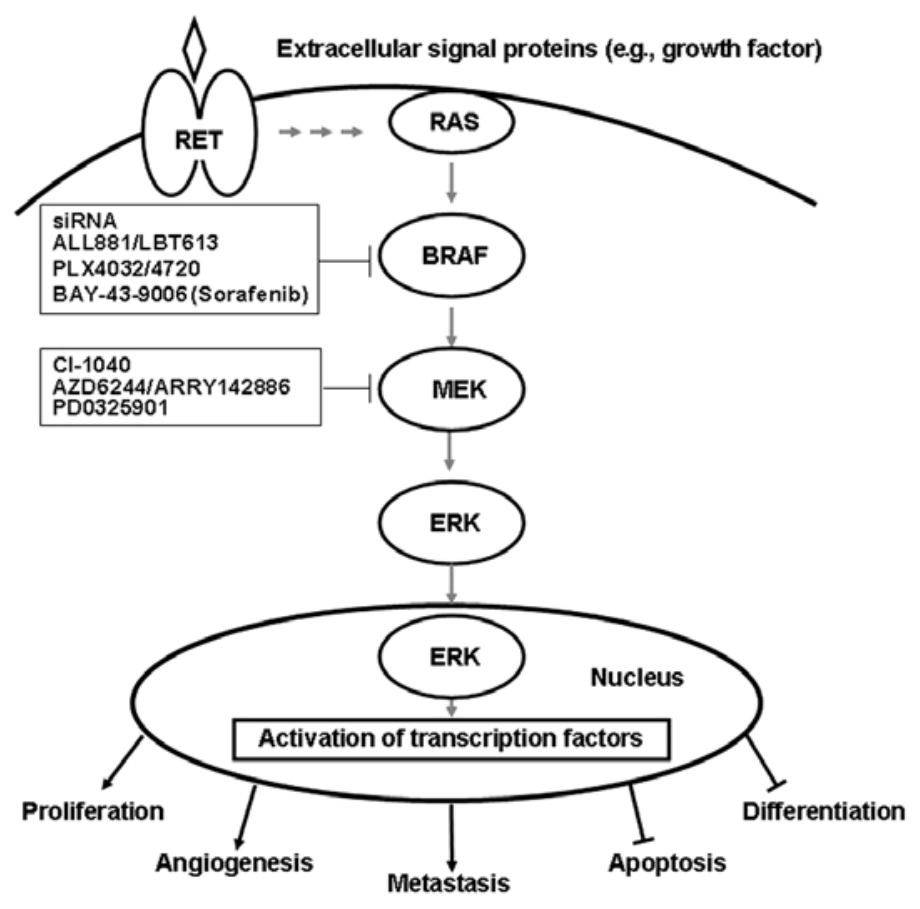

Figure 1. The RAS-RAF-MEK-ERK signaling pathway (MAPK pathway) and molecular inhibitors targeting BRAF mutations. Binding of extracellular signal proteins (for example, growth factors) to the extracellular domain of their membrane tyrosine kinase receptor induces receptor dimerization leading to RASactivation. The active form of RAS, in turn, recruits to the cell membrane and activates RAF family proteins (including BRAF), which trigger the sequential phosphorylation and activation of MEK and ERK. Finally, ERK induces the phosphorylation of several substrates (for example nuclear transcription factors) that ultimately lead to the expression of proteins playing important roles in cell proliferation, angiogenesis, apoptosis, metastasis and differentiation. When BRAF mutation occurs, BRAF kinase is activated and leads to deregulated activation of the downstream pathway and finally to the induction of tumorigenesis and tumor progression. Recently, progress has been made on targeted therapy for mutant BRAF. siRNA, ALL881/LBT613, PLX4032/4720 BAY-43-9006 (Sorafenib), directly targeting mutant BRAF and present different inhibiting potentials. Because recent studies demonstrated that BRAF mutation predicts anti-tumor sensitivity to MEK inhibition, several small inhibitors, such as CI-1040, AZD6244/ARRY142886, and PD0325901, were also studied as effective compound for targeted therapy of mutant BRAF.

reported 13 cases of a new variant of PTC and termed it as Warthin-like papillary carcinoma, owing to its close histological resemblance to Warthin tumor of salivary glands (46). In addition, in some schemes, PTC measuring $<10 \mathrm{~mm}$ in diameter, which is termed papillary thyroid microcarcinoma (PTMC), is also considered as a variant of PTC (47-49).

There seems to exist a tendency that the different genetic alterations in the MAPK pathway are associated with distinct phenotypes of PTC (34). It was found that the RET/PTC1 arrangement is usually associated with the common type of PTC (50-52), whereas the RET/PTC3 is most often found in the solid and tall cell variants of PTC, particularly in the post-Chernobyl setting (53-55). Moreover, the activating point mutations of the RAS gene are particularly frequent in follicular variant of PTC (30).

Similarly, the distribution of the BRAF ${ }^{\mathrm{V} 600 \mathrm{E}}$ mutation in PTC also shows a clear histological subtype-related pattern (34). To date, several studies have addressed the BRAF ${ }^{\mathrm{V} 600 \mathrm{E}}$ mutation according to the histological subtype (24,34,56-62). Lee et al determined that $\mathrm{BRAF}^{\mathrm{V} 600 \mathrm{E}}$ mutation was present in 337 of 570 common type PTC $(59 \%)$, in 34 of 43 tall cell variant (79\%), and in 29 of 172 follicular variants (17\%) (63). It has been suggested that the $\mathrm{BRAF}^{\mathrm{V} 600 \mathrm{E}}$ mutation has a strong association with the classic papillary architecture and tall cell variant of PTC but was detected less frequently in the follicular variant.
PTC often occurs as a microcarcinoma with the diameter $<10 \mathrm{~mm}$. Most reports have shown that papillary thyroid microcarcinoma (PTMC) followed an indolent course. In the most recent study, Lee et al demonstrated that a significant number of PTMC cases exhibited highly aggressive clinicopathological characteristics, such as extrathyroid extension, lymph node metastasis, and advanced disease stage (61). They detected the BRAF ${ }^{\mathrm{V} 600 \mathrm{E}}$ mutation in 64 cases of PTMC and found the frequency of this mutation was $37.5 \%$ (24/64). Similar results have been reported by other investigators using smaller numbers of PTMC cases. Trovisco et al analyzed the BRAF ${ }^{\mathrm{V} 600 \mathrm{E}}$ mutation in different subtypes of PTC and detected this mutation in 4 out of 10 PTMC cases (34). Subsequently, they enlarged their previous series and found that the BRAF ${ }^{\mathrm{V} 600 \mathrm{E}}$ mutation was detected in $43 \%$ of all PTMC cases (60). In addition, Lee et al also reported a similar frequency of $\mathrm{BRAF}^{\mathrm{V} 600 \mathrm{E}}$ mutation in the PTMC patients they analyzed (56). Among all the PTMC studies by Lee et al, the $\mathrm{BRAF}^{\mathrm{V} 600 \mathrm{E}}$ mutation was more frequent and statistically significant when PTMC exhibited stage T3/4, extrathyroid extension, and lymph node metastasis, which suggested that the $\mathrm{BRAF}^{\mathrm{V} 600 \mathrm{E}}$ mutation may be a predictor of highly aggressive PTMC. In addition, the BRAF ${ }^{\mathrm{V} 600 \mathrm{E}}$ mutation of PTMC was reported to show a more aggressive subtype-related pattern, which could also support the relationship between the $\mathrm{BRAF}^{\mathrm{V} 600 \mathrm{E}}$ mutation and PTMC with poor prognosis $(34,60)$. 
Additional studies focused on BRAF ${ }^{\mathrm{V} 600 \mathrm{E}}$ mutation distribution in relatively rare histological subtypes of PTC have also been performed recently. The oncocytic variant of PTC (also known as Hürthle cell carcinoma) is characterized by eosinophilic cytoplasm and may have a papillary or follicular architecture (3). Trovisco et al reported that the BRAF ${ }^{\mathrm{V} 600 \mathrm{E}}$ mutation was present in 6 of 15 cases of the oncocytic variant of PTC (40\%). All of the 6 mutant cases were found in the 11 cases of the oncocytic variant of PTC with a conventional (papillary or mixed papillary/follicular) growth pattern $(55 \%)$, whereas no BRAF ${ }^{\mathrm{V} 600 \mathrm{E}}$ mutation was detected in the 4 cases with a follicular pattern (34). These findings reinforced the strong association between the presence of this mutation and papillary architecture. Warthin-like PTC was first described by Apel et al (46) and is closely related to oncocytic variant PTC but is known as a distinct subtype of PTC in some schemes. They found that the epidemiologic features of this special variant of PTC were similar to the conventional PTC. Only a few studies have analyzed this variant as an independent entity and the BRAF ${ }^{\mathrm{V} 600 \mathrm{E}}$ mutation was detected in 6 out of 8 cases of Warthin-like PTC $(34,60)$. The diffuse sclerosing variant of PTC is a rare subtype, accounting for $\sim 1.8 \%$ of PTC cases in a larger series (62). This subtype tends to occur in young patients and exhibits a higher frequency of cervical and distant metastasis, which is associated with a worse prognosis. However, in contrast to these findings, a prognosis similar to that of conventional PTC has also been reported recently $(64,65)$. In their study, Sheu et al reviewed the 7 reported cases of diffuse sclerosing variant PTC and analyzed them for the $\mathrm{BRAF}^{\mathrm{V} 600 \mathrm{E}}$ mutation. The $\mathrm{BRAF}^{\mathrm{V} 600 \mathrm{E}}$ mutation present in only 2 out of 3 cases reported by Salvatore et al (66), whereas 4 other cases lacked the BRAFV600E mutation. In accordance with the previous findings, all eight diffuse sclerosing variant PTC cases examined in the study of Sheu et al were negative for this mutation but had a relatively high frequency of RET/PTC rearrangement, which may represent the initiating genetic event of this special variant of PTC (62).

As reviewed above, different histological subtypes of PTC have been demonstrated to be associated with different frequencies of $\mathrm{BRAF}^{\mathrm{V} 600 \mathrm{E}}$ mutation. When analyzed without subtype stratification in various reports, the prevalence of the BRAF $^{\mathrm{V} 600 \mathrm{E}}$ mutation may show a wide variation (13).

\section{Prognostic value of the $B R_{A F}{ }^{\mathrm{V} 600 \mathrm{E}}$ mutation}

Although it is relatively indolent and highly curable, up to $10 \%$ of patients with PTC eventually die as a result of this disease (6). Therefore, appropriate initial treatment of patients upon accurate risk stratification and prognostic evaluation are important for reducing the recurrence rate as well as the morbidity and mortality of thyroid cancer (22). Recently, Bai et al reported a novel histological grouping and the identification of two risk groups that were significantly correlated with prognosis and predicted patient outcome in terms of tumor recurrence and cancer-related death (67). Because the BRAF ${ }^{\mathrm{V} 600 \mathrm{E}}$ mutation plays an important role in the carcinogenesis of PTC, it is conceivable that this genetic alteration may be a determinant of the clinical and pathological behavior of PTC and could have prognostic significance for this cancer. Until now, many studies have been performed focusing on the relationship between the BRAF ${ }^{\mathrm{V} 600 \mathrm{E}}$ mutation and high-risk clinicopathological characteristics and the prognosis of PTC (22-24,45,58-61,63,68-81). Although some investigators have failed to reveal a significant association between them, most of the studies from various ethnic and geographical backgrounds have demonstrated a significant association of the $\mathrm{BRAF}^{\mathrm{V} 600 \mathrm{E}}$ mutation with one or more aggressive clinicopathological characteristic or poor prognosis of PTC. For example, in 2007, 12 studies with a total of 1168 patients of PTC were subjected to meta-analysis by Lee et al (63). Their results clearly indicated that the BRAF ${ }^{\mathrm{V} 600 \mathrm{E}}$ mutation of PTC is significantly related to the histological subtype, extra-thyroidal invasion, and advanced clinical stage but not associated with race, age, sex or tumor size. These data strongly supported the view that the BRAFV600E mutation is an important and useful prognostic molecular marker for PTC. This conclusion has been confirmed by another comprehensive review (22). Xing et al analyzed the pooled prognostic data from all published studies and found a significant relationship between the BRAF ${ }^{\mathrm{V} 600 \mathrm{E}}$ mutation and extrathyroid invasion, lymph node metastasis and advanced stage of PTC (III-IV), which is in accordance with the previous study. Most recently, in order to further verify the prognostic significance of the $\mathrm{BRAF}^{\mathrm{V}}{ }^{600 \mathrm{E}}$ mutation in PTC patients, Elisei et al studied 102 PTC patients with a median follow-up of 15 years, which to the best of our knowledge is the longest follow-up reported to date (81). Their study also clearly demonstrated that the $\mathrm{BRAF}^{\mathrm{V} 600 \mathrm{E}}$ mutation is an independent poor prognostic factor in mutation-positive patients, who were not only at a high risk for no cure, but also of death.

Although most studies, as reviewed above, support a relationship between the $\mathrm{BRAF}^{\mathrm{V} 600 \mathrm{E}}$ mutation and high risk clinicopathological characteristics and worse prognosis, it is noteworthy that some other studies have revealed opposing results $(23,24,69,70,76,78)$. For example, recently, Ito et al analyzed 631 cases of PTC for the BRAF ${ }^{\mathrm{V} 600 \mathrm{E}}$ mutation with 83 months follow-up on average in Japan. Their results indicated that the $\mathrm{BRAF}^{\mathrm{V} 600 \mathrm{E}}$ mutation is not related to highrisk clinicopathological features or patient prognosis (23). So far, there is no definitive explanation for these conflicting results, but it might be due to differences among the study populations in terms of case numbers, size, age-distribution, PTC histological subtype variants, underlying genetic backgrounds, and follow-up period $(22,81,82)$.

On the whole, the prognostic value of $\mathrm{BRAF}^{\mathrm{V} 600 \mathrm{E}}$ mutation has been demonstrated by the majority of the studies and it seems to be a potential useful molecular marker and may add a new dimension to the traditional risk evaluation of PTC. With this novel dimension, it will be possible to medically manage patients with PTC more appropriately and further reduce the recurrence rate as well as morbidity and mortality of PTC patients.

\section{Detection of the BRAF ${ }^{\mathrm{V} 600 \mathrm{E}}$ mutation}

Because the $\mathrm{BRAF}^{\mathrm{V} 600 \mathrm{E}}$ mutation plays a major role in tumorigenesis and has a significant prognostic value in PTC, clinical application of $\mathrm{BRAF}^{\mathrm{V} 600 \mathrm{E}}$ mutation detection might be a reliable tool to improve preoperative diagnosis and guide patient 
Table I. Development of detection methods of BRAF mutation in thyroid cancer.

${ }^{\mathrm{a} D S}$, direct sequencing.

management, especially with routine fine-needle aspiration biopsy (FNAB) samples. FNAB is the primary means of distinguishing benign from malignant carcinomas and of guiding therapeutic intervention in thyroid nodules. However, $10-30 \%$ of PTC with indeterminate cytology in FNAB needs genetic diagnostic methods to refine the diagnosis $(20,83)$.

Because of the initial discovery of the $\mathrm{BRAF}^{\mathrm{V} 600 \mathrm{E}}$ mutation occurring in a large series of human cancers (32), much work has been done focusing on the detection BRAF mutations in thyroid tumors recently $(15,16,19,20,84-86)$ (Table I). Direct automatic sequencing is widely accepted as the gold standard for the detection of BRAF mutations. Although this method has high specificity and sensitivity in detecting the BRAF ${ }^{\mathrm{V} 600 \mathrm{E}}$ mutation, it is very time consuming. For this reason, novel mutation detection techniques are needed. Detecting the $\mathrm{BRAF}^{\mathrm{V} 600 \mathrm{E}}$ mutation by polymerase chain reaction restriction fragment length polymorphism (PCR-RFLP) was performed on 137 specimens of FNAB of thyroid nodules by Chung et al (85). The BRAF ${ }^{\mathrm{V} 600 \mathrm{E}}$ mutation was present in $93(83 \%)$ of 112 thyroid cancers. Direct sequencing was demonstrated to be a more reliable method with a sensitivity of $83 \%$ and a specificity (96\%), than PCR-RFLP assay with a sensitivity of $78.6 \%$ and specificity of $80 \%$. In 2006, a simple and rapid method to detect the hot-spot point mutation of the BRAF ${ }^{\mathrm{V} 600 \mathrm{E}}$ mutation in thyroid cancer was reported by Matsukuma et al (84). They simplified universal heteroduplex generator technology (UHG) using single-stranded oligonucleotides with an internal deletion as the generator of loop-bearing heteroduplexes. This modification yields two bands to indicate heterozygosity and one band for homozygosity, enabling more straightforward analysis. This method, designated as a loop-hybrid mobility shift assay (LH-MSA), was developed to detect the BRAF ${ }^{\mathrm{V} 600 \mathrm{E}}$ mutation in 25 PTC cases. The presence of the mutation was observed in $64 \%(16 / 25)$ of cases, which was consistent with the previous sequencing results. This simple LH-MSA detection system may enable rapid and low-cost screening of the $\mathrm{BRAF}^{\mathrm{V} 600 \mathrm{E}}$ mutation in PTC cases. Xing et al evaluated a new colorimetric mutation detection method for thyroid tumors. They demonstrated $100 \%$ sensitivity and $100 \%$ specificity in comparison with conventional DNA sequencing as the gold standard. They also found this novel technique was even more sensitive in detecting the $\mathrm{BRAF}^{\mathrm{V} 600 \mathrm{E}}$ mutation in FNAB specimens than conventional sequencing (19). Mutant allele-specific PCR amplification (MASA) for detection of the BRAF ${ }^{\mathrm{V} 600 \mathrm{E}}$ mutation was reported by Sapio et al. The MASA assay proved to be a more sensitive method than SSCP and DNA sequencing. It was proved that MASA is a specific, sensitive, and reliable method to detect the BRAF ${ }^{\mathrm{V} 600 \mathrm{E}}$ mutation in DNA extracted from different sources (20). Rowe et al and Hay et al reported on the same $\mathrm{BRAF}^{\mathrm{V} 600 \mathrm{E}}$ mutation detection method; LightCycler PCR with allele specific fluorescent probe melting curve analysis (LCPCR) $(15,16)$. They detected the same $\mathrm{BRAF}^{\mathrm{V} 600 \mathrm{E}}$ mutation in PTC, and the results were in $100 \%$ concordance with the previous DNA sequencing results. Most recently, Liao et al reported a square wave stripping voltammetry (SWSV) technique and suggested that it is also a successful method for the detection of BRAF mutations (86).

Although all these detection methods have been demonstrated to be rapid, simple, specific, and sensitive at detecting the $\mathrm{BRAF}^{\mathrm{V} 600 \mathrm{E}}$ mutation, there is no single, generally accepted technique for detecting the $\mathrm{BRAF}^{\mathrm{V} 600 \mathrm{E}}$ mutation. Furthermore, the variation of detection methods may be another reason to explain the striking variation in the prevalence of the BRAF $^{\mathrm{V} 600 \mathrm{E}}$ mutation that has been reported in different studies on PTC.

\section{Novel advantages in BRAF ${ }^{\mathrm{V} 600 \mathrm{E}}$ mutation-targeted therapy}

PTC is not particularly life threatening. Generally in western countries, patients with PTC are treated with thyroidectomy, and then radioiodine $\left({ }^{131} \mathrm{I}\right)$ is administered to remove residual tumor tissue and treat metastatic diseases $(22,87)$. Consequently, the majority of PTC patients can be cured routinely and have relatively good prognosis, with an average 40 -year 
relative survival rate of $84 \%$ (88). In some patients, thyroid cancer is incurable with current treatments and is associated with increased morbidity and mortality either because the tumors are inoperable or fail to absorb radioiodine. In addition, some PTC progresses from well differentiated PTC to PDC or ATC. Because it is difficult to treat these poorly differentiated or anaplastic carcinomas, these patients also have significantly reduced survival rates (87). Therefore, it is important to find new therapeutic approaches for these PTC patients.

The RAS-RAF-MEK-ERK signaling pathway (MAPK pathway), relays extracellular signals from the cell membrane to the nucleus via a cascade of phosphorylation events ultimately promoting cancer initiation and progression. This MAPK pathway is particularly important in PTC because it harbors several activating mutations in the pathway with high prevalence (89). The $\mathrm{BRAF}^{\mathrm{V} 600 \mathrm{E}}$ mutation is the most frequent genetic alteration in the MAPK pathway in PTC. For its high prevalence and high specificity for PTC, the BRAF ${ }^{\mathrm{V} 600 \mathrm{E}}$ mutation plays a unique and fundamental role in PTC. Its mutant protein leads to kinase activity 10.7 times higher than occurs in normal cells and induces hyperactivity of the MAPK pathway promoting tumor development $(31,32)$. Therefore, much work has been done in recent years to investigate the therapeutic potential of targeting mutant BRAF in human thyroid cancers (22).

A recent study by Salvatore et al used RNA interference to evaluate the effect of BRAF knockdown in human anaplastic and papillary thyroid cell lines (90). By siRNA-mediated BRAF knockdown, they showed that $\mathrm{BRAF}^{\mathrm{V} 600 \mathrm{E}}$ mutationexpressing thyroid carcinoma cells depend on continuous BRAF activity for intracellular signaling and cell proliferation. Liu et al used BRAF-specific siRNA expression vectors and were able to establish cell clones with stable knockdown of BRAF (91). They were able to demonstrate that stable BRAF siRNA transfection persistently suppressed the proliferation of thyroid cancer cells carrying the BRAF ${ }^{\mathrm{V} 600 \mathrm{E}}$ mutation even after long-term culture. Inhibition of thyroid cancer cell transformation and growth of xenograft tumors harboring the $\mathrm{BRAF}^{\mathrm{V} 600 \mathrm{E}}$ mutation was also demonstrated by this approach. In another recent study by Liu et al, they showed the restorability of the expression of several key thyroid iodidemetabolizing genes by silencing BRAF in thyroid cancer cells using stable siRNA transfection (92). Thus, all these studies provide the proof-of-concept that BRAF is an important therapeutic target in BRAF-mutation-harboring thyroid cancer. In addition, although RNA interference offers an effortless tool for investigating biological systems by selectively silencing genes, key technical aspects, such as optimization of selectivity, stability, in vivo delivery, efficacy, and safety need to be investigated before RNA interference can become a successful therapeutic strategy. Nevertheless, this area shows a huge potential for the pharmaceutical industry around the globe (93), and this approach may become a useful therapeutic tool for treating thyroid cancer harboring the BRAF ${ }^{\mathrm{V} 600 \mathrm{E}}$ mutation.

Using pharmacologic small molecular inhibitors is another potential approach to suppress activated kinases by interfering with expression of the kinase or interaction with the substrate. To date, various BRAF inhibitors have been reported in thyroid cancer research (90). Examples of such inhibitors are the RAF inhibitors ALL881 and LBT613. Quyang et al examined these inhibitors in rat thyroid PCCL3 cells that had been previously modified to express the $\mathrm{BRAF}^{\mathrm{V} 600 \mathrm{E}}$ mutation, a panel of human thyroid cancer cell lines that expressed mutant BRAF, and finally, tumor xenografts (94). Both compounds inhibit human thyroid tumor cell proliferation in a dose-dependent manner, and in nude mice both retard the growth of thyroid tumor xenografts expressing mutant BRAF. Although ALL881 and LBT613 were demonstrated to affect cell proliferation and tumorigenicity in thyroid cancer cell lines and nude mice, they are reasonably toxic, which has hindered their clinical development (87). Therefore, the development of BRAF inhibitors with low toxicity, high specificity, and high efficacy will be needed for further clinical investigations.

Recently, the development of specific kinase inhibitors targeting BRAF and the V600E allele in particular, has been achieved. One of these is PLX4032, as reported by Sala et al (40). PLX4032 is a highly selective inhibitor of BRAF kinase activity with an $\mathrm{IC}_{50}$ of $44 \mathrm{nmol} / \mathrm{l}$ against the $\mathrm{BRAF}^{\mathrm{V} 600 \mathrm{E}}$ mutant. In their study, Sala et al tested this novel compound on melanoma cell line A375 and on three thyroid cell lines ARO, NPA and TPC-1 (A375, ARO and NPA harbor the $\mathrm{BRAF}^{\mathrm{V} 600 \mathrm{E}}$ mutation). An efficient anti-proliferative activity of PLX4032 was indicated in all cell lines, including A375, $\mathrm{ARO}$ and NPA carrying the BRAF ${ }^{\mathrm{V} 600 \mathrm{E}}$ mutation. The compound was most potent against mutant BRAF in A375 cells whereas thyroid cancer cell lines ARO and NPA were less sensitive and showed similar inhibition. TPC-1 showed an approximately 50 -fold higher $\mathrm{IC}_{50}$. This significant difference can be related to the presence of alternative signaling pathway activated by RET/PTC-1 in the TPC-1 cell line. In addition, PLX4032 promoted apoptotic death in a dose-dependent manner in the melanoma cell line A375; in contrast, in thyroid cancer cell lines NPA and ARO, very little evidence of apoptosis but only an arrest in $\mathrm{G}_{1}$ and a decrease in $\mathrm{S}$ and $\mathrm{G}_{2}-\mathrm{M}$ phase were observed. In TPC-1 cells, neither apoptosis nor cell cycle alteration were observed. Furthermore, the difference in outcome of BRAF inhibition between the melanoma cell line and thyroid cancer cells lines may be explained by the finding that the expression of $\mathrm{p} 21^{\mathrm{CIP} 1 / \mathrm{WAF} 1}$ was regulated in the opposite direction in melanoma and thyroid cancer cells. All of the above results were consistent with the data of silencing of mutant BRAF by short hairpin RNA (shRNA) in the same study. Consequently, combined with its low toxicity, the novel small molecular inhibitor PLX4032 can be a useful therapeutic agent for treating melanoma and thyroid cancer carrying the BRAF ${ }^{\mathrm{V} 600 \mathrm{E}}$ mutation. In fact, PLX4032 is currently undergoing a safety study in patients with solid tumors (40).

Another example of these specific kinase inhibitors targeting BRAF, and the V600E allele in particular, is PLX4720, as reported by Tsai et al (95). They utilized a structure-based small molecular discovery approach to screen $>20,000$ compounds in an effort to identify specific kinase inhibitors that selectively targeted the BRAF V600E allele. Indeed, co-crystallization of candidate molecules with the kinase and subsequent biochemical analysis revealed that PLX4720 was selective for the BRAF allele compared with a 
diverse panel of kinases. The compound inhibited BRAF V600E at low concentration, with weaker effects on the wildtype protein. More importantly, this compound inhibited downstream kinase activity, decreased growth rate, and initiated an apoptotic response only in melanoma cell lines harboring the $\mathrm{BRAF}^{\mathrm{V} 600 \mathrm{E}}$ mutant. In addition, in tumor xenograft models carrying the BRAF ${ }^{\mathrm{V} 600 \mathrm{E}}$ mutant, PLX4720 substantially blocked tumor growth without showing toxicity to the mice. Thus, PLX4720 selectively targets the activated mutant BRAF in melanoma cell lines and subsequently blocks proliferation and causes tumor regression. Although, to date, no study has used this novel inhibitor on thyroid cancer, a similar effect in thyroid cancer cell lines and tumor models may be expected. These findings strongly supported the view that PLX4720 is a promising candidate for human clinical trials; however, to date, no report focusing on its clinical evaluation has been made.

Although the above studies do address the importance of mutant BRAF protein as a therapeutic target in thyroid cancer, several questions still remain (87). BAY43-9006 (Sorafenib) is a multi-kinase inhibitor with potent activity against RAF, VEGF-2, VEGF-3, PDGFRß, FLT-3, and c-KIT kinases (30). BAY43-9006 at doses $>1 \mu \mathrm{M}$ in vitro was effective in inhibiting pERK and growth in BRAF mutant thyroid cancer cell lines (90). Unfortunately, clinical trials using BAY439006 to target BRAF signaling have not been effective except for renal carcinoma (96). Although phase II results for BAY43-9006 in differentiated thyroid cancer have not yet been published, this inhibitor had little or no activity in melanoma patients in a phase II trial, including patients with the BRAF ${ }^{\mathrm{V} 600 \mathrm{E}}$ mutation (97). Discrepancies between preclinical and clinical trials results in terms of effectiveness of shrinking tumors after BRAF inhibition are serious and controversial issues that need resolution (98). Recent preclinical studies combining BAY43-9006 with other agents to increase its efficacy are thought to be a new strategy for making BRAF therapy clinically effective (98). For example, BAY43-9006 has been combined with Rotterlin, a protein kinase $\mathrm{C}$ inhibitor, leading to increased synergistic inhibition of cell proliferation and apoptosis in glioma cells (99). Similarly, systemic liposomal ceramide has been shown to enhance the efficacy of BAY 43-9006 (100). Therefore, targeting mutant BRAF using BAY43-9006 may be more effective in combination with other therapeutic agents rather than alone. However, it still remains to be determined whether these combinations would be more effective in clinical practice (98).

An alternative strategy to block the RAF-MEK-ERK pathway in cancer carrying the BRAF ${ }^{\mathrm{V} 600 \mathrm{E}}$ mutation has focused on the inhibition of MEK (101). MEK1 and MEK2 appear to be the most critical downstream mediators of V600E BRAF signaling (102). Recently, Solit and colleagues demonstrated that BRAF mutation predicts sensitivity to MEK inhibition in a panel of human cancer cell lines of different lineages using the MEK inhibitor CI-1040 (103). Their study showed that pharmacological MEK inhibition potently impaired tumor growth in BRAF mutant xenografts, whereas RAS mutant tumors were only partially inhibited. They used the NCI 60 cell line panel, which does not include thyroid cancer cell lines (104). Following these observations, and while this study was in progress, three groups examined the effect of MEK inhibitors CI-1040, AZD6244 and PD0325901, respectively, on panels of thyroid cancer cell lines with various genotypes of the MAPK pathway and their tumor xenografts $(89,101,104)$. In their study, Liu et al showed that tumor cell proliferation was potently inhibited by CI-1040 in cells harboring the $\mathrm{BRAF}^{\mathrm{V} 600 \mathrm{E}}$ mutation or RAS mutation but not in cells carrying RET/PTC rearrangement or wild-type alleles. Down-regulation of cyclin D1 and re-expression of some thyroid specific genes were also induced by CI-1040 in some $\mathrm{BRAF}^{\mathrm{V} 600 \mathrm{E}}$ mutation-harboring cells, and transformation was inhibited in all cells. CI-1040 also inhibited the growth of xenografts in nude mice (89). This is the first study that demonstrated the potent inhibitory effects of the MEK inhibitor CI-1040, on thyroid cells with BRAF mutation or RAS mutation. As a potent MEK inhibitor, CI-1040 entered phase I and II clinical trials with several human cancers (89). Although excellent patient tolerance, safety profiles, and bioavailablity were observed, disappointingly, no consistent, significant anti-tumor activity was shown, although disease stabilization was seen. This modest response to CI-1040 in these clinical trials might be explained by the fact that the cancers included in the clinical trials mainly included nonsmall cell lung, breast and pancreatic cancer, which all infrequently harbor the $\mathrm{BRAF}^{\mathrm{V} 600 \mathrm{E}}$ mutation. Therefore, given the high prevalence of the BRAFV600E mutation in thyroid cancer and combined with these preclinical studies, Liu et al encouraged a clinical trial on CI-1040 in thyroid cancer patients. Similar results were observed in the studies using other MEK inhibitors, AZD6244 (ARRY-142886) and PD0325901 $(101,104)$. Above all, given the high prevalence of BRAF mutations, these novel MEK inhibitors hold great promise as potentially effective therapeutic agents for thyroid cancers carrying BRAF mutation (22).

\section{Conclusion and perspective}

All of the reviewed clinicopathological and molecular studies strongly indicate that the $\mathrm{BRAF}^{\mathrm{V} 600 \mathrm{E}}$ mutation has a unique and fundamental role in tumorigenesis and the progression of PTC. It is found at all stages of progression of PTC. The prevalence of the BRAFV ${ }^{\mathrm{V} 00 \mathrm{E}}$ mutation has a clear association with the histological subtype of PTC. It has been demonstrated that $\mathrm{BRAF}^{\mathrm{V} 600 \mathrm{E}}$ mutation has a strong association with the classic and tall cell variants of PTC. Although the prognostic significance of the BRAFV ${ }^{\mathrm{V} 00 \mathrm{E}}$ mutation in PTC is still controversial, the majority of studies with relatively long periods of follow-up suggested that the $\mathrm{BRAF}^{\mathrm{V} 600 \mathrm{E}}$ mutation is significantly associated with high-risk clinicopathological characteristics and poor prognosis. BRAF ${ }^{\mathrm{V} 600 \mathrm{E}}$ mutation analysis of FNAB specimens could theoretically help to distinguish between benign and malignant tumors when cytology is indeterminate. Whereas, knowing that poorer prognosis correlated with the mutation, preoperative $\mathrm{BRAF}^{\mathrm{V} 600 \mathrm{E}}$ mutation detection might also be useful for treatment and follow-up planning. Detecting BRAF mutant status is very important, and to date various methods have been proposed with different sensitivities and specificities. However, for widely used diagnostic methods on FNAB specimens, a rapid, simple, and generally accepted method 
should be defined. Finally, this review examined the novel advantage of BRAF ${ }^{\mathrm{V} 600 \mathrm{E}}$ mutation targeted therapy in thyroid cancer. Although it still has some technical challenges, siRNA was demonstrated to be effective by knocking-down the BRAF signal pathway and inducing anti-tumor activity in thyroid cancer cell lines and tumor xenografts. Some small molecular inhibitors were reported to be effective in $\mathrm{BRAF}^{\mathrm{V} 600 \mathrm{E}}$ mutation targeting experiments, but most of them were characterized by significant toxicity, which limited their clinical utility. Very recently, an exciting discovery of a group of small molecular inhibitors with specificity for the V600E BRAF mutant protein was reported. Because of their high specificity and low toxicity, these inhibitors were demonstrated to be a promising candidate for clinical trials in targeting therapy against tumors with the BRAF ${ }^{\mathrm{V} 600 \mathrm{E}}$ mutation. Although a lack of clinical efficacy using BAY43-9006 as a mono-therapy may raise doubts of its therapeutic utility for mutant BRAF, recent preclinical studies combining BAY439006 with other agents were demonstrated to be more effective than using it alone. This combined therapy may be a better choice for inhibiting the BRAF signaling pathway in clinical trials in the future. In addition, potent MEK inhibitors were also demonstrated to be a therapeutic target in thyroid cancer cell lines harboring the $\mathrm{BRAF}^{\mathrm{V} 600 \mathrm{E}}$ mutation. This is another important strategy for treating aggressive PTC and ATC. Therefore, by taking advantage of the novel development of small molecular inhibitors, treatment for aggressive PTC and ATC may be available in the near future.

\section{References}

1. Davies L and Welch HG: Increasing incidence of thyroid cancer in the United States, 1973-2002. JAMA 295: 2164-2167, 2006.

2. Leenhardt L, Grosclaude P and Cherie-Challine L: Increased incidence of thyroid carcinoma in france: a true epidemic or thyroid nodule management effects? Report from the French Thyroid Cancer Committee. Thyroid 14: 1056-1060, 2004.

3. DeLellis RA, Lloyd RV, Heitz PU and Eng C (eds): World Health Organization Classification of Tumours, Pathology and Genetics of Tumours of Endocrine Organs. IARCPress, Lyon, 2004.

4. Hundahl SA, Cady B, Cunningham MP, Mazzaferri E, McKee RF, Rosai J, Shah JP, Fremgen AM, Stewart AK and Holzer S: Initial results from a prospective cohort study of 5583 cases of thyroid carcinoma treated in the united states during 1996. U.S. and German Thyroid Cancer Study Group. An American College of Surgeons Commission on Cancer Patient Care Evaluation study. Cancer 89: 202-217, 2000.

5. Kakudo K, Bai Y, Katayama S, Hirokawa M, Ito Y, Miyauchi A and Kuma K: Classification of follicular cell tumors of the thyroid gland: analysis involving Japanese patients from one institute. Pathol Int 59: 359-367, 2009.

6. Hundahl SA, Fleming ID, Fremgen AM and Menck HR: A National Cancer Data Base report on 53,856 cases of thyroid carcinoma treated in the U.S., 1985-1995. Cancer 83: 26382648,1998

7. Santoro M, Melillo RM, Carlomagno F, Fusco A and Vecchio G: Molecular mechanisms of RET activation in human cancer. Ann NY Acad Sci 963: 116-121, 2002.

8. Greco A, Pierotti MA, Bongarzone I, Pagliardini S, Lanzi C and Della Porta G: TRK-T1 is a novel oncogene formed by the fusion of TPR and TRK genes in human papillary thyroid carcinomas. Oncogene 7: 237-242, 1992.

9. Esapa CT, Johnson SJ, Kendall-Taylor P, Lennard TW and Harris PE: Prevalence of Ras mutations in thyroid neoplasia. Clin Endocrinol (Oxf) 50: 529-535, 1999.

10. Cohen Y, Xing M, Mambo E, Guo Z, Wu G, Trink B, Beller U, Westra WH, Ladenson PW and Sidransky D: BRAF mutation in papillary thyroid carcinoma. J Natl Cancer Inst 95: 625-627, 2003.
11. Kimura ET, Nikiforova MN, Zhu Z, Knauf JA, Nikiforov YE and Fagin JA: High prevalence of BRAF mutations in thyroid cancer: genetic evidence for constitutive activation of the RET/ PTC-RAS-BRAF signaling pathway in papillary thyroid carcinoma. Cancer Res 63: 1454-1457, 2003.

12. Riesco-Eizaguirre G and Santisteban P: New insights in thyroid follicular cell biology and its impact in thyroid cancer therapy. Endocr Relat Cancer 14: 957-977, 2007.

13. Xing M: BRAF mutation in thyroid cancer. Endocr Relat Cancer 12: 245-262, 2005.

14. Miller CJ, Cheung M, Sharma A, Clarke L, Helm K, Mauger D and Robertson GP: Method of mutation analysis may contribute to discrepancies in reports of (V599E)BRAF mutation frequencies in melanocytic neoplasms. J Invest Dermatol 123: 990-992, 2004.

15. Hay R, MacRae E, Barber D, Khalil M and Demetrick DJ: BRAF mutations in melanocytic lesions and papillary thyroid carcinoma samples identified using melting curve analysis of polymerase chain reaction products. Arch Pathol Lab Med 131: 1361-1367, 2007.

16. Rowe LR, Bentz BG and Bentz JS: Detection of BRAF V600E activating mutation in papillary thyroid carcinoma using PCR with allele-specific fluorescent probe melting curve analysis. J Clin Pathol 60: 1211-1215, 2007.

17. Benlloch S, Paya A, Alenda C, Bessa X, Andreu M, Jover R, Castells A, Llor X, Aranda FI and Massuti B: Detection of BRAF V600E mutation in colorectal cancer: comparison of automatic sequencing and real-time chemistry methodology. J Mol Diagn 8: 540-543, 2006.

18. Hayashida N, Namba H, Kumagai A, Hayashi T, Ohtsuru A, Ito M, Saenko VA, Maeda S, Kanematsu T and Yamashita S: A rapid and simple detection method for the BRAF(T1796A) mutation in fine-needle aspirated thyroid carcinoma cells. Thyroid 14: 910-915, 2004.

19. Xing M, Tufano RP, Tufaro AP, Basaria S, Ewertz M, Rosenbaum E, Byrne PJ, Wang J, Sidransky D and Ladenson PW: Detection of BRAF mutation on fine needle aspiration biopsy specimens: a new diagnostic tool for papillary thyroid cancer. J Clin Endocrinol Metab 89: 2867-2872, 2004.

20. Sapio MR, Posca D, Troncone G, Pettinato G, Palombini L, Rossi G, Fenzi G and Vitale M: Detection of BRAF mutation in thyroid papillary carcinomas by mutant allele-specific PCR amplification (MASA). Eur J Endocrinol 154: 341-348, 2006.

21. Saldanha G, Purnell D, Fletcher A, Potter L, Gillies A and Pringle JH: High BRAF mutation frequency does not characterize all melanocytic tumor types. Int J Cancer 111: 705-710, 2004.

22. Xing M: BRAF mutation in papillary thyroid cancer: pathogenic role, molecular bases and clinical implications. Endocr Rev 28 : 742-762, 2007.

23. Ito Y, Yoshida H, Maruo R, Morita S, Takano T, Hirokawa M, Yabuta T, Fukushima M, Inoue H, Tomoda C, Kihara M, Uruno T, Higashiyama T, Takamura Y, Miya A, Kobayashi K, Matsuzuka F and Miyauchi A: BRAF mutation in papillary thyroid carcinoma in a Japanese population: its lack of correlation with high-risk clinicopathological features and diseasefree survival of patients. Endocr J 56: 89-97, 2009.

24. Kim TY, Kim WB, Song JY, Rhee YS, Gong G, Cho YM, Kim SY, Kim SC, Hong SJ and Shong YK: The BRAF mutation is not associated with poor prognostic factors in Korean patients with conventional papillary thyroid microcarcinoma. Clin Endocrinol (Oxf) 63: 588-593, 2005.

25. Zuo H, Nakamura Y, Yasuoka H, Zhang P, Nakamura M, Mori I, Miyauchi A and Kakudo K: Lack of association between BRAF V600E mutation and mitogen-activated protein kinase activation in papillary thyroid carcinoma. Pathol Int 57: 12-20, 2007.

26. Frattini M, Ferrario C, Bressan P, Balestra D, De Cecco L, Mondellini P, Bongarzone I, Collini P, Gariboldi M, Pilotti S, Pierotti MA and Greco A: Alternative mutations of BRAF, RET and NTRK1 are associated with similar but distinct gene expression patterns in papillary thyroid cancer. Oncogene 23: 7436-7440, 2004

27. Soares P, Trovisco V, Rocha AS, Lima J, Castro P, Preto A, Maximo V, Botelho T, Seruca R and Sobrinho-Simoes M: BRAF mutations and RET/PTC rearrangements are alternative events in the etiopathogenesis of PTC. Oncogene 22: 4578-4580, 2003.

28. De Groot JW, Links TP, Plukker JT, Lips CJ and Hofstra RM: RET as a diagnostic and therapeutic target in sporadic and hereditary endocrine tumors. Endocr Rev 27: 535-560, 2006. 
29. Santoro M, Melillo RM and Fusco A: RET/PTC activation in papillary thyroid carcinoma: European Journal of Endocrinology Prize Lecture. Eur J Endocrinol 155: 645-653, 2006.

30. Nikiforov YE: Thyroid carcinoma: molecular pathways and therapeutic targets. Mod Pathol 21 (Suppl. 2): S37-S43, 2008.

31. Tuveson DA, Weber BL and Herlyn M: BRAF as a potential therapeutic target in melanoma and other malignancies. Cancer Cell 4: 95-98, 2003.

32. Davies H, Bignell GR, Cox C, Stephens P, Edkins S, Clegg S, Teague J, Woffendin H, Garnett MJ, Bottomley W, Davis N, Dicks E, Ewing R, Floyd Y, Gray K, Hall S, Hawes R, Hughes J, Kosmidou V, Menzies A, Mould C, Parker A, Stevens C, Watt S, Hooper S, Wilson R, Jayatilake H, Gusterson BA, Cooper C, Shipley J, Hargrave D, Pritchard-Jones K, Maitland N, ChenevixTrench G, Riggins GJ, Bigner DD, Palmieri G, Cossu A, Flanagan A, Nicholson A, Ho JW, Leung SY, Yuen ST, Weber BL, Seigler HF, Darrow TL, Paterson H, Marais R, Marshall CJ, Wooster R, Stratton MR and Futreal PA: Mutations of the BRAF gene in human cancer. Nature 417: 949-954, 2002.

33. Ciampi R, Knauf JA, Kerler R, Gandhi M, Zhu Z, Nikiforova MN, Rabes HM, Fagin JA and Nikiforov YE: Oncogenic AKAP9BRAF fusion is a novel mechanism of MAPK pathway activation in thyroid cancer. J Clin Invest 115: 94-101, 2005.

34. Trovisco V, Vieira de Castro I, Soares P, Maximo V, Silva P, Magalhaes J, Abrosimov A, Guiu XM and Sobrinho-Simoes M: BRAF mutations are associated with some histological types of papillary thyroid carcinoma. J Pathol 202: 247-251, 2004.

35. Moretti S, Macchiarulo A, De Falco V, Avenia N, Barbi F, Carta C, Cavaliere A, Melillo RM, Passeri L, Santeusanio F, Tartaglia M, Santoro M and Puxeddu E: Biochemical and molecular characterization of the novel BRAF(V599Ins) mutation detected in a classic papillary thyroid carcinoma. Oncogene 25 : 4235-4240, 2006.

36. Oler G, Ebina KN, Michaluart P Jr, Kimura ET and Cerutti J: Investigation of BRAF mutation in a series of papillary thyroid carcinoma and matched-lymph node metastasis reveals a new mutation in metastasis. Clin Endocrinol (Oxf) 62: 509-511, 2005

37. Hou P, Liu D and Xing M: Functional characterization of the T1799-1801del and A1799-1816ins BRAF mutations in papillary thyroid cancer. Cell Cycle 6: 377-379, 2007.

38. De Falco V, Giannini R, Tamburrino A, Ugolini C, Lupi C, Puxeddu E, Santoro M and Basolo F: Functional characterization of the novel T599I-VKSRdel BRAF mutation in a follicular variant papillary thyroid carcinoma. J Clin Endocrinol Metab 93: 4398-4402, 2008.

39. Wan PT, Garnett MJ, Roe SM, Lee S, Niculescu-Duvaz D, Good VM, Jones CM, Marshall CJ, Springer CJ, Barford D and Marais R: Mechanism of activation of the RAF-ERK signaling pathway by oncogenic mutations of B-RAF. Cell 116: 855-867, 2004

40. Sala E, Mologni L, Truffa S, Gaetano C, Bollag GE and Gambacorti-Passerini C: BRAF silencing by short hairpin RNA or chemical blockade by PLX4032 leads to different responses in melanoma and thyroid carcinoma cells. Mol Cancer Res 6: 751-759, 2008

41. Ciampi R and Nikiforov YE: RET/PTC rearrangements and BRAF mutations in thyroid tumorigenesis. Endocrinology 148 : 936-941, 2007.

42. Wang X, Wang Q, Hu W and Evers BM: Regulation of phorbol ester-mediated TRAF1 induction in human colon cancer cells through a PKC/RAF/ERK/NF-kappaB-dependent pathway. Oncogene 23: 1885-1895, 2004.

43. Knauf JA, Ma X, Smith EP, Zhang L, Mitsutake N, Liao XH, Refetoff S, Nikiforov YE and Fagin JA: Targeted expression of BRAFV600E in thyroid cells of transgenic mice results in papillary thyroid cancers that undergo dedifferentiation. Cancer Res 65: 4238-4245, 2005

44. Espinosa AV, Porchia L and Ringel MD: Targeting BRAF in thyroid cancer. Br J Cancer 96: 16-20, 2007.

45. Adeniran AJ, Zhu Z, Gandhi M, Steward DL, Fidler JP, Giordano TJ, Biddinger PW and Nikiforov YE: Correlation between genetic alterations and microscopic features, clinical manifestations, and prognostic characteristics of thyroid papillary carcinomas. Am J Surg Pathol 30: 216-222, 2006.

46. Apel RL, Asa SL and LiVolsi VA: Papillary Hurthle cell carcinoma with lymphocytic stroma. 'Warthin-like tumor' of the thyroid. Am J Surg Pathol 19: 810-814, 1995.
47. Fink A, Tomlinson G, Freeman JL, Rosen IB and Asa SL: Occult micropapillary carcinoma associated with benign follicular thyroid disease and unrelated thyroid neoplasms. Mod Pathol 9: 816-820, 1996.

48. Harach HR, Franssila KO and Wasenius VM: Occult papillary carcinoma of the thyroid. A 'normal' finding in Finland. A systematic autopsy study. Cancer 56: 531-538, 1985.

49. Yamamoto Y, Maeda T, Izumi K and Otsuka H: Occult papillary carcinoma of the thyroid. A study of 408 autopsy cases. Cancer 65: 1173-1179, 1990

50. Sugg SL, Ezzat S, Rosen IB, Freeman JL and Asa SL: Distinct multiple RET/PTC gene rearrangements in multifocal papillary thyroid neoplasia. J Clin Endocrinol Metab 83: 4116-4122, 1998.

51. Tallini G, Santoro M, Helie M, Carlomagno F, Salvatore G, Chiappetta G, Carcangiu ML and Fusco A: RET/PTC oncogene activation defines a subset of papillary thyroid carcinomas lacking evidence of progression to poorly differentiated or undifferentiated tumor phenotypes. Clin Cancer Res 4: 287-294, 1998.

52. Soares P, Fonseca E, Wynford-Thomas D and SobrinhoSimoes M: Sporadic ret-rearranged papillary carcinoma of the thyroid: a subset of slow growing, less aggressive thyroid neoplasms? J Pathol 185: 71-78, 1998.

53. Nikiforov YE, Rowland JM, Bove KE, Monforte-Munoz H and Fagin JA: Distinct pattern of ret oncogene rearrangements in morphological variants of radiation-induced and sporadic thyroid papillary carcinomas in children. Cancer Res 57: 1690-1694, 1997.

54. Thomas GA, Bunnell H, Cook HA, Williams ED, Nerovnya A, Cherstvoy ED, Tronko ND, Bogdanova TI, Chiappetta G, Viglietto G, Pentimalli F, Salvatore G, Fusco A, Santoro M and Vecchio G: High prevalence of RET/PTC rearrangements in Ukrainian and Belarussian post-Chernobyl thyroid papillary carcinomas: a strong correlation between RET/PTC3 and the solidfollicular variant. J Clin Endocrinol Metab 84: 4232-4238, 1999.

55. Rabes HM, Demidchik EP, Sidorow JD, Lengfelder E, Beimfohr C, Hoelzel D and Klugbauer S: Pattern of radiationinduced RET and NTRK1 rearrangements in 191 post-Chernobyl papillary thyroid carcinomas: biological, phenotypic, and clinical implications. Clin Cancer Res 6: 1093-1103, 2000.

56. Lee JH, Lee ES, Kim YS, Won NH and Chae YS: BRAF mutation and AKAP9 expression in sporadic papillary thyroid carcinomas. Pathology 38: 201-204, 2006.

57. Riesco-Eizaguirre G, Gutierrez-Martinez P, Garcia-Cabezas MA, Nistal M and Santisteban P: The oncogene BRAF V600E is associated with a high risk of recurrence and less differentiated papillary thyroid carcinoma due to the impairment of $\mathrm{Na}^{+} / \mathrm{I}^{-}$ targeting to the membrane. Endocr Relat Cancer 13: 257-269, 2006.

58. Nikiforova MN, Kimura ET, Gandhi M, Biddinger PW, Knauf JA, Basolo F, Zhu Z, Giannini R, Salvatore G, Fusco A, Santoro M, Fagin JA and Nikiforov YE: BRAF mutations in thyroid tumors are restricted to papillary carcinomas and anaplastic or poorly differentiated carcinomas arising from papillary carcinomas. J Clin Endocrinol Metab 88: 5399-5404, 2003.

59. Namba H, Nakashima M, Hayashi T, Hayashida N, Maeda S, Rogounovitch TI, Ohtsuru A, Saenko VA, Kanematsu T and Yamashita S: Clinical implication of hot spot BRAF mutation, V599E, in papillary thyroid cancers. J Clin Endocrinol Metab 88: 4393-4397, 2003

60. Trovisco V, Soares P, Preto A, De Castro IV, Lima J, Castro P, Maximo V, Botelho T, Moreira S, Meireles AM, Magalhaes J, Abrosimov A, Cameselle-Teijeiro J and Sobrinho-Simoes M: Type and prevalence of BRAF mutations are closely associated with papillary thyroid carcinoma histotype and patients' age but not with tumour aggressiveness. Virchows Arch 446: 589-595, 2005.

61. Lee X, Gao M, Ji Y, Yu Y, Feng Y, Li Y, Zhang Y, Cheng W and Zhao W: Analysis of differential BRAF(V600E) mutational status in high aggressive papillary thyroid microcarcinoma. Ann Surg Oncol 16: 240-245, 2009.

62. Sheu SY, Schwertheim S, Worm K, Grabellus F and Schmid KW: Diffuse sclerosing variant of papillary thyroid carcinoma: lack of BRAF mutation but occurrence of RET/PTC rearrangements. Mod Pathol 20: 779-787, 2007.

63. Lee JH, Lee ES and Kim YS: Clinicopathologic significance of BRAF V600E mutation in papillary carcinomas of the thyroid: a meta-analysis. Cancer 110: 38-46, 2007. 
64. Lam AK and Lo CY: Diffuse sclerosing variant of papillary carcinoma of the thyroid: a 35-year comparative study at a single institution. Ann Surg Oncol 13: 176-181, 2006.

65. Thompson LD, Wieneke JA and Heffess CS: Diffuse sclerosing variant of papillary thyroid carcinoma: a clinicopathologic and immunophenotypic analysis of 22 cases. Endocr Pathol 16: 331-348, 2005

66. Salvatore G, Giannini R, Faviana P, Caleo A, Migliaccio I, Fagin JA, Nikiforov YE, Troncone G, Palombini L, Basolo F and Santoro M: Analysis of BRAF point mutation and RET/ PTC rearrangement refines the fine-needle aspiration diagnosis of papillary thyroid carcinoma. J Clin Endocrinol Metab 89: 5175-5180, 2004.

67. Bai Y, Kakudo K, Li Y, Liu Z, Ozaki T, Ito Y, Kihara M and Miyauchi A: Subclassification of non-solid-type papillary thyroid carcinoma identification of high-risk group in common type. Cancer Sci 99: 1908-1915, 2008.

68. Xu X, Quiros RM, Gattuso P, Ain KB and Prinz RA: High prevalence of BRAF gene mutation in papillary thyroid carcinomas and thyroid tumor cell lines. Cancer Res 63: 4561-4567, 2003.

69. Durante C, Puxeddu E, Ferretti E, Morisi R, Moretti S, Bruno R, Barbi F, Avenia N, Scipioni A, Verrienti A, Tosi E, Cavaliere A, Gulino A, Filetti S and Russo D: BRAF mutations in papillary thyroid carcinomas inhibit genes involved in iodine metabolism. J Clin Endocrinol Metab 92: 2840-2843, 2007.

70. Fugazzola L, Mannavola D, Cirello V, Vannucchi G, Muzza M, Vicentini L and Beck-Peccoz P: BRAF mutations in an Italian cohort of thyroid cancers. Clin Endocrinol (Oxf) 61: 239-243, 2004 .

71. Fugazzola L, Puxeddu E, Avenia N, Romei C, Cirello V, Cavaliere A, Faviana P, Mannavola D, Moretti S, Rossi S, Sculli M, Bottici V, Beck-Peccoz P, Pacini F, Pinchera A, Santeusanio F and Elisei R: Correlation between B-RAFV600E mutation and clinico-pathologic parameters in papillary thyroid carcinoma: data from a multicentric Italian study and review of the literature. Endocr Relat Cancer 13: 455-464, 2006.

72. Jo YS, Li S, Song JH, Kwon KH, Lee JC, Rha SY, Lee HJ, Sul JY, Kweon GR, Ro HK, Kim JM and Shong M: Influence of the BRAF V600E mutation on expression of vascular endothelial growth factor in papillary thyroid cancer. J Clin Endocrinol Metab 91: 3667-3670, 2006.

73. Kebebew E, Weng J, Bauer J, Ranvier G, Clark OH, Duh QY, Shibru D, Bastian B and Griffin A: The prevalence and prognostic value of BRAF mutation in thyroid cancer. Ann Surg 246: 466-471, 2007

74. Kim KH, Kang DW, Kim SH, Seong IO and Kang DY: Mutations of the BRAF gene in papillary thyroid carcinoma in a Korean population. Yonsei Med J 45: 818-821, 2004.

75. Kim TY, Kim WB, Rhee YS, Song JY, Kim JM, Gong G, Lee S Kim SY, Kim SC, Hong SJ and Shong YK: The BRAF mutation is useful for prediction of clinical recurrence in low-risk patients with conventional papillary thyroid carcinoma. Clin Endocrinol (Oxf) 65: 364-368, 2006.

76. Liu RT, Chen YJ, Chou FF, Li CL, Wu WL, Tsai PC, Huang CC and Cheng JT: No correlation between BRAFV600E mutation and clinicopathological features of papillary thyroid carcinomas in Taiwan. Clin Endocrinol (Oxf) 63: 461-466, 2005

77. Lupi C, Giannini R, Ugolini C, Proietti A, Berti P, Minuto M, Materazzi G, Elisei R, Santoro M, Miccoli P and Basolo F Association of BRAF V600E mutation with poor clinicopathological outcomes in 500 consecutive cases of papillary thyroid carcinoma. J Clin Endocrinol Metab 92: 4085-4090, 2007.

78. Park SY, Park YJ, Lee YJ, Lee HS, Choi SH, Choe G, Jang HC, Park SH, Park do J and Cho BY: Analysis of differential BRAF(V600E) mutational status in multifocal papillary thyroid carcinoma: evidence of independent clonal origin in distinct tumor foci. Cancer 107: 1831-1838, 2006.

79. Rodolico V, Cabibi D, Pizzolanti G, Richiusa P, Gebbia N, Martorana A, Russo A, Amato MC, Galluzzo A and Giordano C: BRAF V600E mutation and p27 kip1 expression in papillary carcinomas of the thyroid $\leq 1 \mathrm{~cm}$ and their paired lymph node metastases. Cancer 110: 1218-1226, 2007.

80. Xing M, Westra WH, Tufano RP, Cohen Y, Rosenbaum E, Rhoden KJ, Carson KA, Vasko V, Larin A, Tallini G, Tolaney S, Holt EH, Hui P, Umbricht CB, Basaria S, Ewertz M, Tufaro AP, Califano JA, Ringel MD, Zeiger MA, Sidransky D and Ladenson PW: BRAF mutation predicts a poorer clinical prognosis for papillary thyroid cancer. J Clin Endocrinol Metab 90: 6373-6379, 2005 .
81. Elisei R, Ugolini C, Viola D, Lupi C, Biagini A, Giannini R Romei C, Miccoli P, Pinchera A and Basolo F: BRAF(V600E) mutation and outcome of patients with papillary thyroid carcinoma: a 15-year median follow-up study. J Clin Endocrinol Metab 93: 3943-3949, 2008.

82. Puxeddu E, Durante C, Avenia N, Filetti S and Russo D: Clinical implications of BRAF mutation in thyroid carcinoma. Trends Endocrinol Metab 19: 138-145, 2008.

83. Kim SK, Kim DL, Han HS, Kim WS, Kim SJ, Moon WJ, Oh SY and Hwang TS: Pyrosequencing analysis for detection of a BRAFV600E mutation in an FNAB specimen of thyroid nodules. Diagn Mol Pathol 17: 118-125, 2008.

84. Matsukuma S, Yoshihara M, Kasai F, Kato A, Yoshida A, Akaike M, Kobayashi O, Nakayama H, Sakuma Y, Yoshida T, Kameda Y, Tsuchiya E and Miyagi Y: Rapid and simple detection of hot spot point mutations of epidermal growth factor receptor, BRAF, and NRAS in cancers using the loop-hybrid mobility shift assay. J Mol Diagn 8: 504-512, 2006.

85. Chung KW, Yang SK, Lee GK, Kim EY, Kwon S, Lee SH Park do J, Lee HS, Cho BY, Lee ES and Kim SW: Detection of BRAFV600E mutation on fine needle aspiration specimens of thyroid nodule refines cyto-pathology diagnosis, especially in BRAF600E mutation-prevalent area. Clin Endocrinol (Oxf) 65: 660-666, 2006

86. Liao KT, Cheng JT, Li CL, Liu RT and Huang HJ: Ultrasensitive detection of mutated papillary thyroid carcinoma DNA using square wave stripping voltammetry method and amplified gold nanoparticle biomarkers. Biosens Bioelectron 15: 1899-1904, 2009.

87. Chiloeches A and Marais R: Is BRAF the Achilles' Heel of thyroid cancer? Clin Cancer Res 12: 1661-1664, 2006.

88. Samaan NA, Schultz PN, Hickey RC, Goepfert H, Haynie TP, Johnston DA and Ordonez NG: The results of various modalities of treatment of well differentiated thyroid carcinomas: a retrospective review of 1599 patients. J Clin Endocrinol Metab 75: 714-720, 1992.

89. Liu D, Liu Z, Jiang D, Dackiw AP and Xing M: Inhibitory effects of the mitogen-activated protein kinase kinase inhibitor CI-1040 on the proliferation and tumor growth of thyroid cancer cells with BRAF or RAS mutations. J Clin Endocrinol Metab 92: 4686-4695, 2007

90. Salvatore G, De Falco V, Salerno P, Nappi TC, Pepe S Troncone G, Carlomagno F, Melillo RM, Wilhelm SM and Santoro M: BRAF is a therapeutic target in aggressive thyroid carcinoma. Clin Cancer Res 12: 1623-1629, 2006.

91. Liu D, Liu Z, Condouris S and Xing M: BRAF V600E maintains proliferation, transformation and tumorigenicity of BRAF-mutant papillary thyroid cancer cells. J Clin Endocrinol Metab 92: 2264-2271, 2007

92. Liu D, Hu S, Hou P, Jiang D, Condouris S and Xing M: Suppression of BRAF/MEK/MAP kinase pathway restores expression of iodide-metabolizing genes in thyroid cells expressing the V600E BRAF mutant. Clin Cancer Res 13: 1341-1349, 2007.

93. Pushparaj PN, Aarthi JJ, Manikandan J and Kumar SD: siRNA, miRNA, and shRNA: in vivo applications. J Dent Res 87: 992-1003, 2008.

94. Ouyang B, Knauf JA, Smith EP, Zhang L, Ramsey T, Yusuff N, Batt D and Fagin JA: Inhibitors of Raf kinase activity block growth of thyroid cancer cells with RET/PTC or BRAF mutations in vitro and in vivo. Clin Cancer Res 12: 1785-1793, 2006.

95. Tsai J, Lee JT, Wang W, Zhang J, Cho H, Mamo S, Bremer R, Gillette S, Kong J, Haass NK, Sproesser K, Li L, Smalley KS, Fong D, Zhu YL, Marimuthu A, Nguyen H, Lam B, Liu J, Cheung I, Rice J, Suzuki Y, Luu C, Settachatgul C, Shellooe R, Cantwell J, Kim SH, Schlessinger J, Zhang KY, West BL, Powell B, Habets G, Zhang C, Ibrahim PN, Hirth P, Artis DR, Herlyn M and Bollag G: Discovery of a selective inhibitor of oncogenic B-Raf kinase with potent antimelanoma activity. Proc Natl Acad Sci USA 105: 3041-3046, 2008.

96. Kane RC, Farrell AT, Saber H, Tang S, Williams G, Jee JM, Liang C, Booth B, Chidambaram N, Morse D, Sridhara R, Garvey P, Justice R and Pazdur R: Sorafenib for the treatment of advanced renal cell carcinoma. Clin Cancer Res 12: 7271-7278, 2006.

97. Eisen T, Ahmad T, Flaherty KT, Gore M, Kaye S, Marais R, Gibbens I, Hackett S, James M, Schuchter LM, Nathanson KL, Xia C, Simantov R, Schwartz B, Poulin-Costello M, O'Dwyer PJ and Ratain MJ: Sorafenib in advanced melanoma: a Phase II randomised discontinuation trial analysis. Br J Cancer 95: 581-586, 2006 
98. Madhunapantula SV and Robertson GP: Is B-Raf a good therapeutic target for melanoma and other malignancies? Cancer Res 68: 5-8, 2008.

99. Jane EP, Premkumar DR and Pollack IF: Coadministration of sorafenib with rottlerin potently inhibits cell proliferation and migration in human malignant glioma cells. J Pharmacol Exp Ther 319: 1070-1080, 2006.

100. Sharma A, Trivedi NR, Zimmerman MA, Tuveson DA Smith CD and Robertson GP: Mutant V599EB-Raf regulates growth and vascular development of malignant melanoma tumors. Cancer Res 65: 2412-2421, 2005

101. Ball DW, Jin N, Rosen DM, Dackiw A, Sidransky D, Xing M and Nelkin BD: Selective growth inhibition in BRAF mutant thyroid cancer by the mitogen-activated protein kinase kinase 1/2 inhibitor AZD6244. J Clin Endocrinol Metab 92: 4712-4718, 2007.
102. Garnett MJ and Marais R: Guilty as charged: B-RAF is a human oncogene. Cancer Cell 6: 313-319, 2004.

103. Solit DB, Garraway LA, Pratilas CA, Sawai A, Getz G, Basso A, Ye Q, Lobo JM, She Y, Osman I, Golub TR, Sebolt-Leopold J, Sellers WR and Rosen N: BRAF mutation predicts sensitivity to MEK inhibition. Nature 439: 358-362, 2006.

104.Leboeuf R, Baumgartner JE, Benezra M, Malaguarnera R, Solit D, Pratilas CA, Rosen N, Knauf JA and Fagin JA: BRAFV600E mutation is associated with preferential sensi-tivity to mitogen-activated protein kinase kinase inhibition in thyroid cancer cell lines. J Clin Endocrinol Metab 93: 2194-2201, 2008 . 